\title{
Touch dominates haptic estimates of discordant visual-haptic size
}

\author{
WAYNE A. HERSHBERGER \\ Northerm Illinois University, DeKalb, Illinois \\ and \\ GIOVANNI F. MISCEO \\ Benedictine College, Atchison, Kansas
}

\begin{abstract}
Observers ( 72 college students) estimated the size of plastic squares that they held in their fingers and simultaneously viewed through a reducing lens that halved the squares' visual size. The squares were grasped from below through a cloth that prevented direct sight of the hand. Each estimate was a match selected later, either haptically or visually, from a set of comparison squares. Vision dominated the visual estimates and touch dominated the haptic estimates, whether or not the observers knew in advance which type of estimate they would be asked to make. Neither modality inherently dominates perceived size.
\end{abstract}

The present experiments replicate and extend the findings of experiments by Klein (1966) and by McDonnell and Duffett (1972), providing evidence that touch dominates vision when adult observers make haptic estimates of the size of discordant stimuli whose visual and haptic sizes differ. This evidence is at odds with Rock and Victor's (1964) claim that "conflict between visual and tactual size is ... resolved more or less completely in favor of visual size" (p. 595). The present results demonstrate, further, that the dominant modality (vision or touch) corresponds to the type of comparison stimuli (visual or haptic) that observers are asked to use to render their estimates. That is, when visual and haptic size conflict, neither modality is inherently dominant.

Although Rock and Victor's (1964) corollary claim about conflicting shape has been brought into question by the work of Heller (1983, 1992; cf. McGurk \& Power, 1980; Power, 1980, 1981; Power \& Graham, 1976), the present research does not address that controversy. Nor does the present research address the question of intermodal dominance in cases of conflicting information regarding an object's orientation, location, or texture. For reviews of that extensive literature, see Welch and Warren (1980), and Warren and Rossano (1991). The present study focuses exclusively on studies of conflicting size, because apparent size distinguishes itself from the other perceptual attributes (apparent shape, etc.) in exhibiting no essential intermodal dominance. The present data, to-

Preliminary reports of Experiments 1 and 2 were presented at the 33rd Annual Meeting of the Psychonomic Society, St. Louis, November 1992, and the 66th Annual Meeting of the Midwestern Psychological Association, Chicago, May 1994, respectively. Correspondence should be addressed to W. A. Hershberger, Department of Psychology, Northern Illinois University, DeKalb, IL 60115 (e-mail: wah@niu.edu). gether with those they replicate, show that conflict between visual and tactual size is not necessarily resolved in favor of visual size.

\section{Rock and Victor's Study}

Rock and Victor's (1964) assertion that vision dominates haptic estimates of size was based on a simple experiment, described by Rock (1966, pp. 223-225, 244 249 ), in which naive observers were asked to grasp a 25 -mm square piece of plastic (i.e., $25 \mathrm{~mm}$ on a side) through a silk cloth while simultaneously viewing it for $5 \mathrm{sec}$ through a negative lens that reduced the square's virtual image to about half size (the size of the virtual square was estimated on visual control trials to be $15.8 \mathrm{~mm}$ on a side). With the cloth preventing sight of their hand, the naive observers noticed nothing unusual about the discordant square. Further, when the observers were subsequently asked to estimate the size of the discordant standard square by selecting a match from among a set of haptic comparison squares (which they could touch but not see) the observers selected comparison squares having a mean size of $16.2 \mathrm{~mm}$, which is remarkably similar to $15.8 \mathrm{~mm}$. Some of Rock and Victor's observers estimated the size of the discordant standard square by drawing (i.e., visualizing) it; they, too, estimated the standard square to be about half size.

Because their observers were generally unaware of the intermodal conflict, Rock and Victor (1964) presumed that the discordant square felt as small as it looked; that is, they interpreted their data to mean that vision had actually distorted, or partially captured (Hay, Pick, \& Ikeda, 1965), touch. Alternately, it is possible that Rock and Victor's naive observers simply disregarded the haptic information in the first place and used the haptic comparison squares later merely to render a cross-modal match of the standard's remembered visual size (for a 
consideration of cross-modal matching, see Milewski \& Iaccino, 1982). Consistent with this interpretation is the finding of Klatzky, Lederman, and Matula (1993) that college students judging the relative size of two visible objects rarely use touch except "to bring the objects into better view" (p. 738). This is not to say that adults necessarily make poor haptic estimates of size; even with lumps of rubber glued to their fingertips, adults can make very accurate haptic estimates of size (Chan, Carello, \& Turvey, 1990). Rather, holding something is not the same as haptically estimating its size, and we know only that Rock and Victor's observers were holding the discordant square.

In order to exclude the latter interpretation, which trivializes Rock and Victor's (1964) data, observers must be encouraged to notice the haptic information. Klein (1966) and McDonnell and Duffett (1972) did this simply by asking their observers to examine the discordant standard(s) more than once, making a haptic size estimate each time. Consequently, we can be sure that their observers were examining the discordant stimulus for the purpose of estimating its size. In contrast, we do not know what Rock and Victor's (1964) subjects were trying to do. Thus, if one is concerned about the relative dominance of visual and haptic information in mediating intentional estimates of size, the relevant findings are those reported by Klein (1966) and by McDonnell and Duffett (1972). Before we proceed to a detailed consideration of those two studies, however, a few additional methodological considerations merit attention.

\section{Methodological Considerations}

Estimating the size of a discordant standard stimulus by selecting a match from among a set of haptic comparison stimuli (the method used by Rock \& Victor, 1964) is not to be confused with estimating the size of a standard stimulus (either visual or discordant) by selecting a match from among a set of discordant comparison stimuli (see, e.g., Fishkin, Pishkin, \& Stahl, 1975; Kinney \& Luria, 1970; Rock, Mack, Adams, \& Hill, 1965). The latter paradigm, unlike the former, does not oblige observers to make judgments of touch in the first place and therefore does not necessarily reflect vision's effects on touch. For example, Kinney and Luria had individuals estimate the size of four familiar coins (remembered standards) by selecting corresponding disks from a set of 16 comparison disks viewed under water (discordant comparisons). Although the experimental participants were asked to pick up each coin-size disk and hand it to the experimenter when called for, they were not obliged to use any information about haptic size in performing this task. Therefore, it is gratuitous to suppose that their results have anything to do with haptic size.

Instructing observers to judge a standard's felt, as opposed to visual, size may help, but does not necessarily solve the problem (see, e.g., Walker, 1971, 1972). For instance, consider Walker's (1971) Experiment 1: Observers haptically estimated the length of a pair of vertical test rods viewed against an illusory geometric back- ground (Ponzo or Müller-Lyer) by alternately (1) grasping the pair of rods, one with each hand, and (2) adjusting an invisible pair of variable comparisons, one with each hand. Although the observers were allowed to reach back and forth between the test rods and the variable comparisons as often as they needed, the test rods were continuously visible, inviting simple cross-modal matching. Walker instructed the observers to adjust the variable comparisons until each felt the same length the corresponding test rods felt, but there was nothing to prevent their cross-modal matching (making the comparison rods feel the same length as the standards look). Neither do verbal magnitude estimates of discordant visual-haptic standards (see, e.g., R. Teghtsoonian \& M. Teghtsoonian, 1970) necessarily reflect judgments of touch, or vision's effects on touch.

The preferred method for assessing vision's effects on touch is the one used by Rock and Victor (1964), but with repeated measures to encourage the observers to notice the discordant haptic information (i.e., observers examining a discordant standard for the first time may fail to register its haptic size, but after being asked to select a haptic comparison stimulus that matches the size of the previously examined standard, they are more likely to note the standard's haptic size on subsequent trials). In other words, the preferred method is the one used by Klein (1966) and by McDonnell and Duffett (1972). Therefore, the particulars of these two studies merit our careful consideration. In both of these studies, the discordant standard stimulus comprised a pair of objects attached to the front and rear surface of a screen or panel so as to simulate a single object protruding through a hole; the observers felt the one in back while viewing the one in front.

\section{Klein's Study}

Klein (1966) tested five groups of 24 observers each whose mean chronological ages were 9.5, 11.5, 13.8, 15.9 , and 18.0 years. Each observer viewed the crosssection of a 2.54-mm-diameter peg while simultaneously feeling a $1.75-\mathrm{mm}$-diameter peg. While examining this discordant peg, the observer simultaneously judged its diameter by selecting one of eight haptic comparison stimuli with the other hand. In addition to the discordant condition (D), visual and haptic controls were used. In the visual control condition (V), the peg was only viewed, and in the haptic control condition $(\mathrm{H})$, it was only felt. In both control conditions, the comparison stimuli remained haptic. Every observer made four consecutive estimates in each condition. Averaging these four estimates, a single "visual capture score," $(D-H) /(V-$ $H$ ), was calculated for each observer. The value of this ratio ranges from 1.0 to $0.0(1.0=$ total visual dominance, $0.0=$ total haptic dominance, and $0.5=$ equal dominance or no dominance of either type). The group means, from youngest to oldest, were 0.36, 0.51, 0.37, 0.30 , and 0.14 . Since none of these ratios is significantly greater than 0.5 , none of Klein's five age groups evinced visual dominance. Instead, the two oldest groups, espe- 
cially the young adults (i.e., 18-year-olds), evinced haptic dominance; the means for both groups were significantly $(p<.05)$ less than 0.5 .

The present interpretation of Klein's (1966) data is essentially new. Although Welch and Warren (1980) included Klein's dissertation in their comprehensive review of the literature, they characterized Klein's data, regrettably, as he had himself, simply as reflecting a "partial visual bias... [ranging from] about $50 \%$ visual capture in 11 -year-olds to $20 \%$ in 18 -year-olds" (Welch \& Warren, 1980 , p. 643). Using the term bias in this way is regrettable because it misrepresents Klein's results. In general, Klein's subjects' mean size estimates were biased toward the haptic, not the visual, size of the discordant stimulus. Calling such biases "visual" is confusing, to say the least.

\section{McDonnell and Duffett's Study}

McDonnell and Duffett's (1972) experimental observers ( 10 college students) estimated the length of 10 wooden blocks. Each block was $50.8 \mathrm{~mm}$ wide and $19.05 \mathrm{~mm}$ thick. The blocks were mounted in pairs to opposite sides of five panels. The pairs of blocks were laid back to back so as to simulate a composite block of discordant length. Because the panel was $6.35 \mathrm{~mm}$ thick, the composite thickness of each discordant block was $19.05+19.05+$ $6.35=44.45 \mathrm{~mm}$. The lengths (in millimeters) of the pairs of blocks glued to the five panels were 50.8 and $50.8,44.45$ and $57.15,38.1$ and $63.5,31.75$ and 69.85 , and 25.4 and 76.2 (note that the mean lengths of the shorter and longer blocks were, thus, 38.1 and $63.5 \mathrm{~mm}$, respectively). Each panel could be fit, as a leaf, into the top of a table with either the shorter or the longer block facing down for haptic examination. Half of the observers always felt the shorter block while viewing the longer block (Group SH), and half always felt the longer block while viewing the shorter block (Group LH). Each observer estimated the length of each of the five standard stimuli twice, once visually and once haptically, each time by selecting a matching block from a set of 15 comparison blocks. The observers were not told which type of estimate they were to make on a given trial until after they had completed a 2-min examination of the discordant standard stimulus.

Haptic estimates of the length of the discordant standard stimulus averaged (arithmetic mean) 36.83, 39.37, $40.64,40.64$, and $44.45 \mathrm{~mm}$ for the 5 observers in Group SH (whose discordant standards actually averaged $38.1 \mathrm{~mm}$ haptically and $63.5 \mathrm{~mm}$ visually), and $62.23,62.23,60.96,60.96$, and $45.72 \mathrm{~mm}$ for the $5 \mathrm{ob}-$ servers in Group LH (whose discordant standards actually averaged $63.5 \mathrm{~mm}$ haptically and $38.1 \mathrm{~mm}$ visually). If the last observer may be said to have evinced visual dominance, all the rest (i.e., 9 of the 10 subjects) exhibited some degree of haptic dominance; further, this sample ratio, $9 / 10$, is significantly greater than $1 / 2$, the ratio that would be expected under the null hypothesis of no real dominance of either type $(p<.05$, binomial sign test). Thus, McDonnell and Duffett found a preponder- ance of haptic dominance among their adult observers, as had Klein. McDonnell and Duffett's (1972) 1 exceptional observer appears to have been haptically matching the visual rather than the haptic size of the standard square. Rock and Victor's (1964) method is preferred to the others mentioned above because it requires observers to use haptic comparison stimuli and thereby encourages their matching the standard's haptic size, but it does not force the observer to judge the standard's haptic size.

Welch and Warren (1980) have suggested that McDonnell and Duffett's (1972) (and, by implication, Klein's, 1966) failure to replicate Rock and Victor's (1964) finding may be attributable, at least in part, to their use of an ineffective technique for creating intersensory conflict. In this regard, they cited Miller (1972), who had concluded, from his own research with conflicting shapes, that this technique (viewing one object while feeling another) does not actually produce conflict (even when the objects are mounted to a single panel directly opposite each other) unless observers are explicitly told that they will be "seeing and feeling identical halves of the same object" (Miller, 1972, p. 121). Although McDonnell and Duffett (1972) claimed that their observers "did not expect the top and bottom blocks to differ" (p. 174), they did not tell them that they would be seeing and feeling identical halves of the same object.

A testable implication of Welch and Warren's (1980) interpretation of McDonnell and Duffett's (1972) (and Klein's, 1966) findings is that such effects are not replicable using the optical technique employed by Rock and Victor (1964). Rock and Victor's subjects grasped a square piece of plastic while simultaneously viewing it through a reducing lens. This optical technique allows observers to see the entire standard stimulus, not just part of it protruding through a hole, so it is immediately apparent to the observer that the stimulus is a monolithic unit that can be examined, at once, both visually and haptically. Further, using a stimulus that is thin enough to be regarded as 2-dimensional (i.e., a square) leaves no doubt that the four edges being viewed from above are the same four edges that are being grasped from below (i.e., rectangles have only four edges). Furthermore, using a square (i.e., a rectangle whose four edges are of equal length) means that physical size is determined by a single metric: edge length. Thus the visual-haptic conflict engendered by a reducing lens, used in the manner of Rock and Victor (1964), is tightly joined: Touch registers one value and sight registers another value of the very same physical variable, edge length. Welch and Warren (1980) suggested that it was the absence of this tightly joined conflict in the studies of Klein (1966) and McDonnell and Duffett (1972) that accounts for their failure to replicate Rock and Victor's results. This implies, conversely, that an experiment using Rock and Victor's optical technique would fail to replicate the findings of Klein (1966) and McDonnell and Duffett (1972). The present experiments were designed to test this implication. 


\section{The Present Study}

We created visual-haptic size conflict in the present two experiments by using a stigmatic reducing lens, as had Rock and Victor (1964). (Rock and Victor also created visual-haptic shape conflict by using an astigmatic cylindrical lens - but that is another matter altogether.)

In Experiment 1, half of the observers used haptic comparison stimuli and half used visual comparison stimuli to estimate the size of various discordant standard stimuli. Prior to these experimental trials, some of the observers participated in control trials in which they estimated either the visual or haptic size of the standard stimuli by using the same type of comparison stimuli. This procedure allowed us to assess the effects of prior practice in making haptic or visual size estimates upon observers' subsequent size estimates of discordant standard stimuli. In addition, the control data provide objective estimates of the apparent size of our two types of standards, visual and haptic.

In Experiment 2, observers estimated the size of various discordant standard stimuli using haptic comparison stimuli on some trials and visual comparison stimuli on others without knowing which they would be asked to use on a particular trial until after they had examined the discordant standard. To provide baselines for comparison, observers in two additional groups used either haptic or visual comparison stimuli throughout.

\section{EXPERIMENT 1}

\section{Method}

Observers. Forty-eight college students, 23 males and 25 females, enrolled in general psychology at Benedictine College participated as psychophysical observers estimating the size of discordant standard stimuli. They were randomly assigned to one of two experimental groups, one that used haptic comparison stimuli to render estimates (Group D/H, comprising 13 males and $11 \mathrm{fe}$ males), and one that used visual comparison stimuli (Group D/V, comprising 10 males and 14 females).

Discordant standard stimuli. Each observer was asked to estimate the size of five different squares that had been cut from a sheet of black plastic $5 \mathrm{~mm}$ thick. The five squares measured 40 , $45,50,55$, and $60 \mathrm{~mm}$ on a side. Each square was presented for inspection in a large box (approximately $48 \times 48 \times 48 \mathrm{~cm}$ ) with a conical viewing tube centered in its top. The conical viewing tube was $75 \mathrm{~mm}$ long; its inside diameter was $76 \mathrm{~mm}$ at one end (the mouth into which observers peered) and $51 \mathrm{~mm}$ at the other end (the base). A meniscus lens $52 \mathrm{~mm}$ in diameter was wedged into the base of the tube. This lens had a focal length of minus $238 \mathrm{~mm}$. The square being examined was positioned face up $238 \mathrm{~mm}$ directly beneath the lens and held there by means of a long rod attached to its edge. To view a square, observers positioned the bridge of their nose about $35 \mathrm{~mm}$ from the mouth of the viewing tube; the reducing lens mounted in the base of the tube (about $110 \mathrm{~mm}$ from the observer's eyes) afforded a binocular view of the square's virtual image (the size of a square's virtual image depends on the distance between the lens and the square, not the distance between the lens and the eyes). A loosely fitting opaque white cloth suspended directly beneath the square acted as a false floor below which the observers could insert a hand. The viewing tube afforded a view of the square and the cloth, but nothing else. The observers viewed each square through the reducing lens while simultaneously grasping the square from below through the white cloth, preventing sight of their hand. The observers were instructed to grasp the squares at the edges with their thumb and fingertips. Because the square was situated in the secondary focal plane of the lens, the virtual square visible to the observer was half size (or one quarter of the area). Thus, the visual and haptic sizes were discordant. The observers were instructed to examine each standard square until they had a good idea of its size.

Comparison stimuli. On each trial the observer estimated the size of the discordant standard stimulus by selecting a match from among a set of 12 comparison squares ranging in size from 15 to $70 \mathrm{~mm}$ in $5-\mathrm{mm}$ increments. There were two such sets, one for visual comparison and one for haptic comparison. The two sets of comparison stimuli were arrayed differently to minimize crossmodal response generalization.

The visual comparison squares, labeled with letters alphabetically in the order of their size, were mounted in a circular array on the wall directly behind the observers' position for examining a standard stimulus. Thus, simply by turning around, the observers could use saccadic eye movements to quickly select a match and call out its letter.

The haptic comparison squares, suspended on posts, were mounted in a horizontal row in the order of their size inside a box with a curtained opening allowing the observers to reach in and touch the squares without seeing them. This box was located immediately to the right of the observers' position for examining a standard stimulus. The ordinal arrangement of the squares allowed the observers to anticipate where in the array a match would be found, and thus to find it quickly. The observers selected the haptic stimulus with the same hand they had used to examine the discordant standard-their writing hand.

Test trials. Each observer judged the size of each of the five standard squares six times in a randomized sequence, with the restriction that each standard was judged once in each successive five-trial block. Because each of these five standard squares was judged once in each five-trial block, the objective size of the average haptic standard stimulus was $50 \mathrm{~mm}$ for each block of trials, and the size of the average visual standard stimulus (being reduced to half size) was $25 \mathrm{~mm}$ for each block of trials.

Half (i.e., 24) of the observers (Group D/V) selected a match from among the set of visual comparison squares. The other half (Group D/H) selected a match from among the set of haptic comparison squares. The observers turned to the comparison stimuli only after having finished their examination of the discordant standard stimulus.

Control trials. Prior to their 30 test trials estimating the size of the discordant standard stimuli, one third of the observers in each of the two experimental groups were given 20 control trials using the visual comparison stimuli to estimate the visual size of the standard squares (i.e., they looked at the standard squares but did not touch them and then selected a match from the set of visual comparison stimuli) - the VSVC control group, comprising 7 males and 9 females. Another one third of each group was given 20 control trials using the haptic comparison stimuli to estimate the haptic size of the standard squares (i.e., they touched the standard squares but did not look at them and then selected a match from the set of haptic comparison stimuli) - the HSHC control group, comprising 7 males and 9 females. The remaining one third of each group had no practice of either kind - the NoPE control group, comprising 9 males and 7 females. During these control trials, as during the subsequent test trials described above, the five standard stimuli were presented in a randomized sequence with the restriction that each square was presented once in each successive five-trial block.

\section{Results}

Control data. The data from the 20 control trials were subjected to a mixed three-way analysis of variance 
(ANOVA): two active control groups (VSVC and HSHC), four trial blocks, and five standard stimuli. The analysis yielded four significant effects $(\alpha=.05$, as always): a main effect for group $[F(1,30)=1,556, p<$ $.0001]$, a main effect for stimulus $[F(4,120)=400, p<$ $.0001]$, a group $\times$ stimulus interaction $[F(4,120)=37.61$, $p<.0001]$, and a group $\times$ block interaction $[F(3,90)=$ $6.58, p<.0004]$. The first three effects are illustrated in Figure 1, which shows the apparent sizes of the five haptic and five visual stimuli. In all 10 cases, the mean apparent size was slightly less than the corresponding objective size. The grand mean of Group HSHC's haptic estimates was $48.3 \mathrm{~mm}(S E=.44)$, a bit less than the objective size of the average standard square of $50 \mathrm{~mm}$. The grand mean of Group VSVC's visual estimates was $22.7 \mathrm{~mm}(S E=.26)$, a bit less than the objective size of the average square's virtual image of $25 \mathrm{~mm}$. The group $\times$ stimulus interaction is an artifact of the restricted range of the reduced virtual images $(20-30 \mathrm{~mm})$ relative to the range of the squares themselves $(40-60 \mathrm{~mm})$.

The group $\times$ block interaction is illustrated in Figure 2. A test of the simple main effects of block showed that the block effect was statistically reliable only for Group HSHC's haptic estimates of haptic size $[F(3,45)=$ $7.91, p<.0002$ ]; pairwise contrasts among the HSHC means showed that only the first block differed reliably from the others. Group VSVC evinced no adaption to the lens during the four blocks of practice $[F(3,45)<1]$.

Test data. The data from the 30 test trials were subjected to a mixed four-way ANOVA: two experimental groups $(\mathrm{D} / \mathrm{H}$ and $\mathrm{D} / \mathrm{V})$, three types of prior practice (HSHC, VSVC, and NoPE), six trial blocks, and five stan-



Figure 1. Experiment 1: The mean apparent haptic size of each standard square estimated haptically (HSHC), the mean apparent visual size of each standard square estimated visually (VSVC), and the mean apparent discordant size of each standard square estimated haptically $(\mathrm{D} / \mathrm{H})$ and visually $(\mathrm{D} / \mathrm{V})$. The real size of each square is indicated by the solid line. The size of each square's reduced virtual image is indicated by the dotted line labeled "Half."



Figure 2. Experiment 1: The mean apparent haptic size of the average standard square estimated haptically (HSHC), the mean apparent visual size of the average standard square estimated visually (VSVC), and the mean apparent discordant size of the average standard square estimated haptically $(\mathrm{D} / \mathrm{H})$ and visually $(D / V)$, plotted by trial block. The objective size of the average standard square was $50 \mathrm{~mm}$ haptically, and $25 \mathrm{~mm}$ visually.

dard stimuli. The analysis yielded four significant effects (the same four as above): a main effect for group $[F(1,42)=27.16, p<.0001]$, a main effect for stimulus $[F(4,168)=455.49, p<.0001]$, a group $\times$ stimulus interaction $[F(4,168)=5.98, p<.0002]$, and a group $\times$ block interaction $[F(5,210)=9.95, p<.0001]$. The first three effects are illustrated in Figure 1, which shows the apparent size of each of the five discordant squares as estimated haptically by Group $\mathrm{D} / \mathrm{H}$ and visually by Group D/V. The size estimate for each discordant square reflects the type of comparison stimuli the observers used to render their estimates. The group $\times$ stimulus interaction reflects the artifact of the restricted range of the virtual images, which is also visible in the control data. Discounting that artifact, it is clear that the responsemode effect does not vary with size of the standard square. Group D/H evinced incomplete haptic dominance. Group D/V evinced incomplete visual dominance. These opposite response-mode effects are approximately equal in magnitude, leaving the grand mean of all estimates relatively undisturbed; that is, the grand mean of the test data $(36.7 \mathrm{~mm}, S E=.26)$ is about the same as the grand mean of the control data $(35.5 \mathrm{~mm}, S E=.24)$.

The group $\times$ block interaction is illustrated in Figure 2, which shows that the mean apparent size of the discordant squares depended on the sensory modality the observers used to render their size estimates. The group using the haptic modality evinced incomplete haptic dominance and the group using the visual modality evinced incomplete visual dominance. Further, as the observers in these two groups repeatedly estimated the size of the discordant standard stimuli, either haptically or visually, their size estimates tended to more closely approximate the square's corresponding objective size, 
either haptic or visual. An analysis of the simple main effects of the interaction revealed a significant trial-blocks effect for both the haptic $[F(5,105)=6.19, p<.0001]$ and the visual $[F(5,105)=3.92, p<.01]$ modalities.

\section{Discussion}

The haptic estimates summarized in Figures 1 and 2 are entirely consistent with the findings reported by McDonnell and Duffett (1972) and by Klein (1966), despite the fact that we used Rock and Victor's (1964) optical technique for creating intersensory size conflict. Thus, contrary to Welch and Warren's (1980) speculation, the haptic dominance found by McDonnell and Duffett and by Klein does not appear to be an artifact of their special method (viewing one block of wood while feeling another).

Although Experiment 1 was not designed to replicate Rock and Victor's (1964) experiment, associate editor Lester Krueger and two anonymous reviewers thoughtfully suggested that we look at our observers' first-trial estimates of the discordant squares. Because our observers judged different standards on the first trial, we normalized their estimates by calculating a relative dominance ratio $(\mathrm{RDR})$ for each individual: $\mathrm{RDR}=(\mathrm{DSi}-$ VSVCi)/(HSHCi - VSVCi), where DSi is the particular discordant square being judged (the $i^{\text {th }}$ ), HSHCi is Group HSHC's mean estimate of that same square's haptic size, and VSVCi is Group VSVC's mean estimate of that same square's visual size. Each observer's first-trial RDR is shown in Table 1. An RDR greater than .5 signifies some degree of haptic dominance, and an RDR less than .5 signifies some degree of visual dominance. A twoway ANOVA (three practice groups $\times$ two test modes) of these RDR data yielded no significant effect. Further, the mean RDR for all 48 observers $(.479, S E=0.039)$ was not significantly different from .5 . This implies that if the two functions in Figure 2, labeled $\mathrm{D} / \mathrm{H}$ and $\mathrm{D} / \mathrm{V}$, were extrapolated back to the first trial they might share

Table 1

Relative Dominance Ratio for Each Observer's First Test Trial, Grouped by Type of Prior Practice (HSHC, VSVC, or NoPE) and Test Mode (h or v)

\begin{tabular}{cccccc}
\hline $\mathrm{HSHC} / \mathrm{h}$ & $\mathrm{HSHC} / \mathrm{v}$ & $\mathrm{VSVC} / \mathrm{h}$ & $\mathrm{VSVC} / \mathrm{v}$ & NoPE$/ \mathrm{h}$ & NoPE/v \\
\hline 0.36 & 0.88 & 0.20 & 1.05 & 0.36 & 0.29 \\
0.56 & 0.09 & 0.70 & 0.13 & 0.52 & 0.24 \\
0.68 & 0.89 & 0.29 & 0.20 & 0.48 & 0.65 \\
0.59 & 0.21 & 0.59 & 0.87 & 0.13 & 0.20 \\
0.73 & 0.34 & 0.07 & 0.40 & 0.52 & 0.29 \\
0.65 & 0.09 & 0.59 & 0.88 & 0.56 & 0.43 \\
0.73 & 0.21 & 0.87 & 0.52 & 0.56 & 0.13 \\
0.56 & 0.68 & 0.87 & 0.59 & 0.56 & -0.02 \\
{$[0.608]$} & {$[0.423]$} & {$[0.525]$} & {$[0.582]$} & {$[0.463]$} & {$[0.276]$} \\
$0.042)$ & $(0.121)$ & $(0.107)$ & $(0.118)$ & $(0.053)$ & $(0.070)$ \\
$7 / 8$ & $3 / 8$ & $5 / 8$ & $5 / 8$ & $5 / 8$ & $1 / 8$ \\
\hline
\end{tabular}

Note - Group means and their standard errors are shown in brackets and parentheses, respectively. The last entry in each column is the fraction of RDRs in that column that are greater than .5 (leaning toward haptic size). the same value, with this value being roughly equivalent to $35.5 \mathrm{~mm}$, the grand mean of the control data. In other words, at the very beginning of the experiment, the response mode bias may have been nearly nil, leaving the two modalities equally potent.

Getting back to Rock and Victor's (1964) experiment: Our observers who were most similar to theirs were the 16 observers in the NoPE control group. Our NoPE observers who made visual estimates on the first test trial corresponded to Rock and Victor's subjects who estimated the size of the discordant square by drawing (i.e., visualizing) it-and a large fraction of them (7/8) exhibited visual dominance, as had Rock and Victors's subjects. However, most (5/8) of our NoPE observers who made haptic estimates on the first test trial did not exhibit visual dominance; their mean RDR (.463, $S E=$ 0.053 ) was not significantly different from .5 . Thus, our first-trial results do not fully replicate Rock and Victor's. Of course, our observers were instructed to note the size of the standard square, whereas Rock and Victor's were not. Therefore, whether or not Rock and Victor's results can be replicated remains to be tested.

\section{EXPERIMENT 2}

The observers in Experiment 1 used the same set of comparison stimuli from trial to trial (either haptic or visual) and therefore could anticipate the modality of the match they would be asked to make. Consequently, they may have adopted a judgmental set, paying attention to the modality corresponding to the comparison stimuli from which they were to select a match, while ignoring the discordant cross-modal information. This, obviously, would reduce the intersensory conflict. What would happen if observers did not know which set of comparison stimuli they would be asked to use on a given trial until after they had examined the discordant standard stimulus for that trial? Experiment 2 addressed that question. McDonnell and Duffett (1972) found haptic dominance using such a procedure, but their method of inducing intersensory conflict is in question.

The students participating in Experiment 2 were assigned to one of three groups. Observers in one group did not know which type of comparison stimuli they would be asked to use on a given trial until after they had examined the discordant standard. To provide baselines for comparison, observers in the two additional groups used either haptic or visual comparison stimuli throughout.

\section{Method}

Observers. Twenty-four college students, 12 males and 12 females, enrolled in general psychology at Benedictine College participated as psychophysical observers estimating the size of discordant standard stimuli. Each student was randomly assigned to one of three groups $(\mathrm{D} / \mathrm{V}, \mathrm{D} / \mathrm{H}$, or $\mathrm{DX})$ of 8 students each: Group D/V ( 4 males, 4 females) made their estimates visually; Group D/H ( 3 males, 5 females) made their estimates haptically; and Group DX ( 5 males and 3 females) made their estimates visually on half of the trials (DX/V) and haptically on the other half 
(DX/V) - without knowing which until after they had completed their examination of the discordant standard square.

Standard and comparison stimuli. Standard and comparison stimuli were the same as those used in Experiment 1 .

Procedure. The observers in Groups $\mathrm{D} / \mathrm{H}$ and $\mathrm{D} / \mathrm{V}$ judged the size of each of the five standard squares four times in a randomized sequence, with the restriction that each standard was judged once in each successive five-trial block. (The size of the standard square was varied only to get the observer to make a fresh estimate each trial; we did not analyze the data by size, because that would merely introduce an artifact, the one involving range noted above.) $\mathrm{Ob}$ servers in Group D/V selected a match from among the set of visual comparison squares. Those in Group D/H selected a match from among the set of haptic comparison squares. As in Experiment 1, the observers turned to the comparison stimuli only after having finished their examination of the discordant standard squares.

The observers in Group DX judged the size of each of the five standard squares eight times in a randomized sequence, with the restriction that each standard was judged twice in each successive 10 -trial block, once haptically and once visually. Further, the observers in Group DX were not told which set of comparison stimuli they were to use on a given trial until after they had completed their examination of the discordant standard stimulus for that trial.

\section{Results}

Figure 3 shows the mean apparent size of the average standard square as estimated by each group during each block of trials (Group DX generated two estimates during each block, one visual, DX/V, and one haptic, DX/H). The data for Groups D/V and D/H (each of which used only one comparison modality) were combined and analyzed separately from the data for Group DX (which used different comparison modalities on different trials).

Groups D/V and D/H. A 2 (groups) $\times 4$ (blocks) ANOVA of the data for Groups $\mathrm{D} / \mathrm{V}$ and $\mathrm{D} / \mathrm{H}$ yielded a

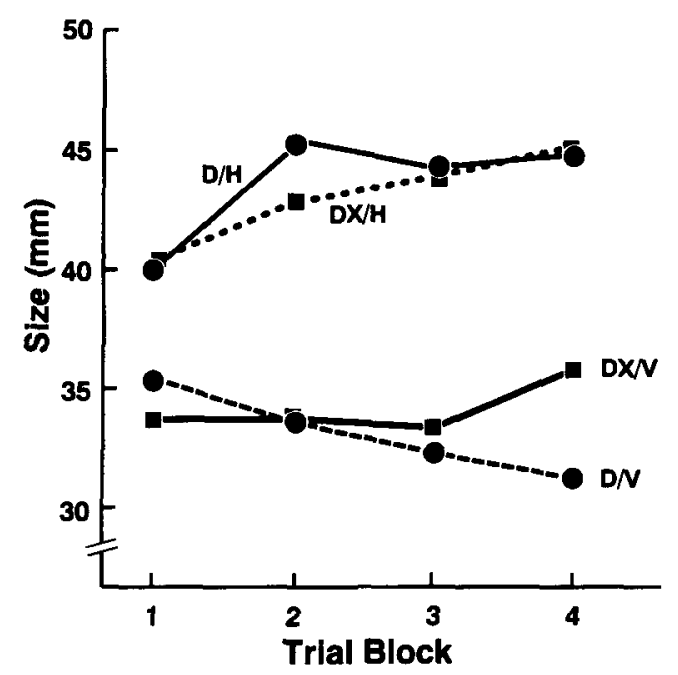

Figure 3. Experiment 2: The mean apparent size of the average discordant standard square plotted as a function of the nature of the estimate and the trial block. Group D/H made haptic estimates, Group D/V made visual estimates, and Group DX made haptic estimates on some trials $(\mathrm{DX} / \mathrm{H})$ and visual estimates on others $(\mathrm{DX} / \mathrm{V})$. The objective size of the average standard square was $50 \mathrm{~mm}$ haptically, and $25 \mathrm{~mm}$ visually. significant main effect of group $[F(1,14)=34.25, p<$ $.0001]$ and a significant group $\times$ block interaction $[F(3,42)=8.87, p<.0001]$. These results parallel those of Experiment 1.

Group DX. A 2 (modalities) $\times 4$ (blocks) ANOVA of the data for Group DX yielded one significant effect, a main effect of modality $[F(1,7)=28.54, p<.001]$. Group DX's mean haptic estimate pooled over blocks $(43.2 \mathrm{~mm})$ did not differ significantly from Group D/H's mean estimate $(43.5 \mathrm{~mm})$. Likewise, Group DX's mean visual estimate pooled over blocks $(34.6 \mathrm{~mm})$ did not differ significantly from Group D/V's mean estimate $(33.5 \mathrm{~mm})$.

Group DX's estimates differed from those of Groups $\mathrm{D} / \mathrm{H}$ and $\mathrm{D} / \mathrm{V}$ primarily in terms of the presence or $\mathrm{ab}$ sence of a modality $\times$ block interaction. More specifically, the haptic and visual dominance shown by Groups $\mathrm{D} / \mathrm{H}$ and $\mathrm{D} / \mathrm{V}$, respectively, became more pronounced with practice, whereas the haptic and visual dominance shown by Group DX on the haptic and visual trials, respectively, did not significantly change across trial blocks. The hint of a block main effect in Group DX's data, visible in Figure 3, was not significant, although it looks as if continued practice with both comparison modalities might eventually have produced a significant asymmetric bias, with touch biasing vision more than vision biasing touch.

\section{GENERAL DISCUSSION}

The results of Experiments 1 and 2, taken together, demonstrate that the sort of haptic dominance found by McDonnell and Duffett (1972) and by Klein (1966) is not an artifact of their special method. Therefore, Rock and Victor's (1964) blanket claim that "conflict between visual and tactual size is ... resolved more or less completely in favor of visual size" (p. 595) is unwarranted.

The principal general finding of the present experiments is that, on average, observers' size estimates of discordant standard stimuli (comprising conflicting visual and haptic sizes) are dominated either by vision or touch, with the dominant modality corresponding to the type of comparison stimuli used by the observers to render their size estimates. This is true even when observers do not know which type of comparison they will be asked to make until after they have examined the discordant standard. Therefore, the effect does not reflect a simple attentional bias, such as ignoring the discordant information provided by the alternate modality. On any given trial, the observers in Group DX were prepared to evince either visual or haptic dominance; the type of dominance observed on any particular trial was determined later by the set of comparison stimuli used on that trial.

The perceived size of a discordant standard stimulus appears to be registered as a bivariate observation. That is, the size is registered both visually and haptically, with each impression biasing (partially capturing) the other. 
Ogawa (1976) reported similar findings and concluded that conflicting visual and haptic size resolves itself as a compromise, the value of which varies with the comparison modality. In much of the present data, the biasing is more or less symmetrical: Figures 1 and 2 show that discordant haptic information biases visual size estimates by as much as discordant visual information biases haptic size estimates. Because neither modality captures the other completely, a discordant stimulus should actually appear to be discordant, although not as discordant as the corresponding objective stimuli or their corresponding sensations. For example, if one looks at the last block of trials in Figure 2 (i.e., Block 6), one can see that the apparent discordance (discordant/haptic minus discordant/ visual) was only about $11 \mathrm{~mm}$, on average, whereas the intersensory discordance (haptic/haptic minus visual/ visual) was about $26 \mathrm{~mm}$, on average.

Continuing with the data from Block 6 , it may be noted further that, were the observers in the discordant/ haptic group to close their eyes while grasping the standard square, its apparent size should increase from about $42 \mathrm{~mm}$ (discordant/haptic, Block 6) to $49 \mathrm{~mm}$ (haptic/ haptic). Rock and Victor (1964) observed such an effect in a follow-up procedure administered to some of their observers, who, by this time, were no longer naive. The observers were instructed to alternately open and close their eyes while grasping the discordant standard, and to judge whether it felt any different under the two conditions. More than half of the participants tested in this way said the standard square felt larger when their eyes were closed. The others did not report any definite impression. Rock and Victor interpreted this finding to mean that the discordant visual information resulting from the reducing lens actually altered the felt (haptic) size of the standard, more or less as our data suggest. This process also appears to have been reflected in Tastevin's (1937) finding that an unseen box held between two fingers feels less than full size when plaster replicas of the fingers are viewed holding a smaller box.

Yet, there is no empirical warrant for Rock and Victor's (1964) blanket claim that conflicts between visual and tactual size are resolved in favor of visual size. Only if the observer is making visual estimates of the size of a discordant standard are those estimates likely to be more similar to the visual than to the haptic size of the standard. This sort of visual dominance is possible whenever observers are able to make their estimates of size visually (see, e.g., Rock et al., 1965), but such limited visual dominance as this does not warrant Rock and Victor's blanket claim.

It should be noted, however, that one might find evidence for Rock and Victor's (1964) claim in developmental studies such as Klein's (1966). Klein's younger observers did not exhibit the haptic dominance displayed by his 18 -year-olds. The children in Klein's youngest group were 9-year-olds. Would haptic information be even less influential with 5-year-olds? The experimental literature includes a number of developmental studies of intermodal conflict involving young children (see, e.g., Hatwell, 1987; McGurk \& Power, 1980), but, with the exception of Klein's, none have investigated the question of perceived size using Rock and Victor's method, as we have done here.

Considering the various types of intermodal conflict that have been investigated during this century, including shape, texture, orientation, and location (Warren \& Rossano, 1991; Welch \& Warren, 1980), it is ironic that visual-haptic size conflict should be the one type of intersensory discordance that does not tend to resolve itself in favor of an inherently dominant modality. To this day, writers addressing questions of intermodal dominance or primacy (e.g., Heller \& Schiff, 1991; Millar, 1994; Schwartz, 1994) credit Berkeley (1709/1950) with originating the idea, and the idea that most concerned Berkeley was apparent size. Berkeley argued that distance of regard and, therefore, size, are not directly visible; he claimed that they are visualized only by means of mental algorithms taught by a dominant sense of touch. Accordingly, Rock and Victor (1964) noted that their findings of visual dominance (with respect either to conflicting size or to conflicting shape) contradicted Berkeley's hoary thesis. The present results, which are at odds with Rock and Victor's claims about conflicting size (conflicting shape is another matter), imply that Berkeley's error was not in supposing that haptic size dominates visual size (it can sometimes, as our results show), but in supposing that one sensory modality, either vision or touch, is inherently subservient to the other in estimating size.

\section{REFERENCES}

BERKELEY, G. (1950). An essay towards a new theory of vision. New York: Dutton. (Original work published 1709)

Chan, T.-C., Carello, C., \& Turvey, M. T. (1990). Perceiving object width by grasping. Ecological Psychology, 2, 1-35.

Fishkin, S. M., Pishkin, V., \& Stahl, M. L. (1975). Factors involved in visual capture. Perceptual \& Motor Skills, 40, 427-434.

Hatwell, Y. (1987). Motor and cognitive functions of the hand in infancy and childhood. International Journal of Behavioral Development, 10, 509-526.

HAY, J. C., PICK, H. L., JR., \& IKEDA, K. (1965). Visual capture produced by prism spectacles. Psychonomic Science, 2, 215-216.

Heller, M. A. (1983). Haptic dominance in form perception with blurred vision. Perception, 12, 607-613.

Heller, M. A. (1992). Haptic dominance in form perception: Vision versus proprioception. Perception, 21, 655-660.

Heller, M. A., \& SCHIFF, W. (Eds.) (1991). The psychology of touch. Hillsdale, NJ: Erlbaum.

KinNey, J. A. S., \& LuRIA, S. M. (1970). Conflicting visual and tactualkinesthetic stimulation. Perception \& Psychophysics, 8, 189-192.

Klatzky, R. L., Lederman, S. J., \& Matula, D. E. (1993). Haptic exploration in the presence of vision. Journal of Experimental Psychology: Human Perception \& Performance, 19, 726-741.

KLEIN, R. E. (1966). A developmental study of perception under conditions of conflicting sensory cues. Dissertation Abstracts, 27 , 2162B-2163B. (University Microfilms No. 66-12213)

MCDonnell, P. M., \& Duffett, J. (1972). Vision and touch: A reconsideration of conflict between the two senses. Canadian Journal of Psychology, 26, 171-180.

MCGuRK, H., \& Power, R. P. (1980). Intermodal coordination in 
young children: Vision and touch. Developmental Psychology, 16, 679-680.

MilewsKi, A. E., \& IACCINo, J. (1982). Strategies in cross-modality matching. Perception \& Psychophysics, 31, 273-275.

Millar, S. (1994). Understanding and representing space. Oxford: Oxford University Press, Clarendon Press.

Miller, E. A. (1972). Interaction of vision and touch in conflict and nonconflict form perception tasks. Journal of Experimental Psychology, 96, 114-123.

OGaWA, T. (1976). Perceptual conflict between vision and touch. Japanese Journal of Psychology, 47, 97-101.

PoWER, R. P. (1980). The dominance of touch by vision: Sometimes incomplete. Perception, 9, 457-466.

POWER, R. P. (1981). The dominance of touch by vision: Occurs with familiar objects. Perception, 10, 29-33.

Power, R. P., \& Graham, A. (1976). The dominance of touch by vision: Generalization of the hypothesis to a tactually experienced population. Perception, 5, 161-166.

Rock, I. (1966). The nature of perceptual adaptation. New York: Basic Books.

Rock, I., Mack, A., Adams, L., \& Hill, A. L. (1965). Adaptation to contradictory information from vision and touch. Psychonomic Science, 3, 435-436.

ROCK, I., \& VICTOR, J. (1964). Vision and touch: An experimentally created conflict between the two senses. Science, 143, 594-596.

Schwartz, R. (1994). Vision. Oxford: Blackwell.

TASTEVIN, J. (1937). En partant de l'experience d'Aristote. L'Encephale, 1, 57-84, 140-158.

Teghtsoonian, R., \& Teghtsoonian, M. (1970). Two varieties of perceived length. Perception \& Psychophysics, 8, 389-392.

Walker, J. T. (1971). Visual capture in visual illusions. Perception $\&$ Psychophysics, 10, 71-74.

WALKER, J. T. (1972). Natural visual capture in bilateral length comparisons. Perception \& Psychophysics, 11, 247-251.

WARREN, D. H., \& RosSANO, M. J. (1991). Intermodality relations: Vision and touch. In M. A. Heller \& W. Schiff (Eds.), The psychology of touch (pp. 119-137). Hillsdale, NJ: Erlbaum.

WELCH, R. B., \& WARREN, D. H. (1980). Immediate perceptual response to intersensory discrepancy. Psychological Bulletin, 88, 638-667.

(Manuscript received September 11, 1995; revision accepted for publication December 27, 1995.) 